\title{
SESSION 2: Intestinal cation transport
}

\section{Intestinal calcium absorption 2011}

\author{
George L Kellett
}

Department of Biology, University of York, York YO10 5DD, UK.

\section{Challenges to the dogma}

The current dogma states that there are two pathways of intestinal $\mathrm{Ca}^{2+}$ absorption [1]. The first is the facilitated diffusion pathway. It is a secondary active, transcellular process with entry into enterocytes occurring through TRPV6 in the apical membrane. Entry is driven by the electrochemical gradient, comprising a $\mathrm{Ca}^{2+}$ gradient of $\sim 10^{5}$-fold (cytosol $\sim 0.1 \mu \mathrm{M}$ ) and a $\mathrm{V}_{\mathrm{m}}$ of $-47 \mathrm{mV}$ (apical membrane potential, cytosol $-\mathrm{ve}$ ) under resting conditions. Diffusion across the cytosol is facilitated by calbindin- $\mathrm{D}_{9 \mathrm{~K}}$ and $\mathrm{Ca}^{2+}$ exits across the basolateral membrane, via the plasma membrane $\mathrm{Ca}^{2+}$-ATPase, PCMA1b. The pathway is dependent on vitamin $\mathrm{D}$ and activated by low dietary $\mathrm{Ca}^{2+}$.

The second pathway of intestinal $\mathrm{Ca}^{2+}$ absorption is paracellular flow through tight junctions [2]. It is often described as vitamin D-independent and driven by a downhill gradient of $\mathrm{Ca}^{2+}$ and solvent drag. The transcellular component is saturable, whereas the paracellular component is non-saturable (linear). The TRPV6 transcellular pathway is predominant in duodenum, but the paracellular pathway is predominant in jejunum and the only component in ileum. Because the transit times for chyme through jejunum and ileum are much longer than that through duodenum, the current view is that $80 \%$ of absorption occurs by paracellular flow.

The dogma of transcellular absorption has been brought into question by studies on genetically modified mice. Of note, single knockouts for either TRPV6 or calbindin- $\mathrm{D}_{9 \mathrm{~K}}$ have no effect on $\mathrm{Ca}^{2+}$ homeostasis or absorption. Even more startling is the observation that $\mathrm{Ca}^{2+}$ absorption in TRPV6/calbindin- $\mathrm{D}_{9 \mathrm{~K}}$ double knockout mice is still some $50-60 \%$ of control. As noted, the findings challenge "the dogma of the need for TRPV6 and calbindin-D9K for $1,25(\mathrm{OH})_{2} \mathrm{D}_{3}$-induced calcium absorption [3]."

What has not previously been appreciated is that knockout studies question the very basis of the argument for paracellular flow. Thus, assignment of the linear component to paracellular absorption was made on the basis that ileum does not contain calbindin- $\mathrm{D}_{9 \mathrm{~K}}$, which, in the dogma, is essential for $\mathrm{Ca}^{2+}$ absorption: since absorption could not be transcellular, it must be paracellular [2]. Now that calbindin- $\mathrm{D}_{9 \mathrm{~K}}$ is no longer deemed essential, the argument falls.

\section{Something fundamental is missing from the dogma}

One way forward is to recognize that something fundamental is missing from the dogma. The facilitated diffusion pathway is often presented and taken simply as "the pathway of intestinal $\mathrm{Ca}^{2+}$ absorption." Yet, TRPV6 is activated by hyperpolarization and such conditions only apply between 
digestive periods. Paracellular flow through tight junctions is said to provide the other half of the story, for tight junctions are 'open' under depolarizing conditions. However, in all the key experiments on which the case for paracellular flow was built, the solutions used for absorption determinations contained no glucose or other nutrient. Thus the conditions were relatively polarizing; indeed, tight junctions were in a 'closed' state.

Together, the papers on TRPV6 and paracellular flow probably account for some $90 \%$ of the literature. The unavoidable conclusion is that the dogma of intestinal $\mathrm{Ca}^{2+}$ absorption in 2011 does not begin to address the depolarizing conditions of digestion, when luminal $\mathrm{Ca}^{2+}$ is at its highest. If an L-type channel were present in intestine, then that might provide a way out of the dilemma. However, the conventional view for some 30 years has been that L-type channels are not present in intestine. Reasons advanced are that epithelial cells are activated by hyperpolarization, that attempts to detect Ltype channels with blockers such as nifedipine and verapamil have been unsuccessful and that the voltage-current activation curve of the classical cardiac channel $\left(\mathrm{Ca}_{v} 1.2\right)$ is 'wrong' for intestine, that is, $\mathrm{Ca}_{\mathrm{v}} 1.2$ covers a voltage range which much positive than resting $\mathrm{V}_{\mathrm{m}}$.

\section{$\mathrm{Ca}_{\mathrm{v}} 1.3$ is present in the apical membrane of small intestine}

We discovered $\mathrm{Ca}_{\mathrm{v}} 1.3$ while working on jejunal glucose absorption. There are two pathways of glucose absorption, one through SGLT1 and the other the facilitative glucose transporter GLUT2 [4]. They can be readily resolved by the inhibitors, phloridzin and phloretin, respectively. Transport of glucose through SGLT1 induces rapid trafficking of GLUT2 to the apical membrane, so that at glucose concentrations between $30-100 \mathrm{mM}$, much higher than the $30 \mathrm{mM}$ required to saturate SGLT1, the flux through apical GLUT2 becomes several-fold greater than through SGLT1. As glucose concentration decreases with absorption, so GLUT2 traffics back to sub-apical membrane vesicles. The process requires two signals. The first must be entry of $\mathrm{Ca}^{2+}$, because GLUT2 insertion is dependent on PKC $\beta$ II and cytoskeletal rearrangement. The second is provided by sweet taste receptors, since the artificial sweetener sucralose doubles glucose absorption by doubling apical GLUT2 without effect on SGLT1 [4].

The immediate question is how $\mathrm{Ca}^{2+}$ enters the enterocyte to stimulate apical GLUT2 insertion under highly depolarizing conditions - the dogma provides no satisfactory explanation. Homology-based PCR demonstrated the presence of $\mathrm{Ca}_{\mathrm{v}} 1.3$ in jejunal mucosa and Western blotting confirmed its presence in the apical membrane [5]. Crucially immunocytochemistry revealed that $\mathrm{Ca}_{\mathrm{v}} 1.3$ was located at highest levels in the heart of the digestive centre from mid-jejunum to mid ileum. There was little in duodenum and caecum, where most previous trials of L-type blockers had been tested. In rat jejunum perfused in vivo with high glucose, $\mathrm{Ca}^{2+}$ absorption displayed L-type characteristics. Active absorption of $1.25 \mathrm{mM} \mathrm{Ca}^{2+}$ was maximal at $20 \mathrm{mM}$ glucose; absorption was inhibited by nifedipine and verapamil and activated with Bay K-8644, which have no effect on TRPV6. Ca $\mathrm{C}_{\mathrm{v}} 1.3$ is 10 -fold less 
sensitive to nifedipine than $\mathrm{Ca}_{\mathrm{v}} 1.2$. Depolarization of the apical membrane by inhibition of SGLT1 with phloridzin strongly inhibited $\mathrm{Ca}^{2+}$ absorption.

The observations are consistent with the idea that glucose transport through SGLT1 depolarizes the apical membrane to activate $\mathrm{Ca}_{\mathrm{v}} 1.3$ and permit $\mathrm{Ca}^{2+}$ entry. Any possible involvment of paracellular flow was ruled out by showing that the myosin light chain kinase inhibitor, ML-7, blocked myosin phosphorylation and cytoskeletal rearrangement without effect on $\mathrm{Ca}^{2+}$ absorption [6]. Other arguments against paracellular flow include the observation that $\mathrm{Ca}^{2+}$ and water absorption are not correlated and that mannitol clearance is negligible in vivo and unaffected by ML-7; thus solvent drag plays no significant role. The transepithelial voltage gradient $\left(\mathrm{V}_{\mathrm{te}}\right)$, is serosa-positive, $+10.3 \mathrm{mV}$ at high glucose; $\mathrm{V}_{\text {te }}$ therefore drives $\mathrm{Ca}^{2+}$ secretion; even maximal luminal $\mathrm{Ca}^{2+}$ concentrations, at $1-5$ $\mathrm{mM}$, are too low to overcome $\mathrm{V}_{\text {te }}$.

Strong support for a role for $\mathrm{Ca}_{\mathrm{v}} 1.3$ in intestinal transcellular $\mathrm{Ca}^{2+}$ absorption comes from recent knockdown studies in Caco-2 cells, which contain $\mathrm{Ca}_{\mathrm{v}} 1.3$, TRVP6, calbindin- $\mathrm{D}_{9 \mathrm{~K}}$ and PMCA1b. The studies showed that prolactin-stimulated $\mathrm{Ca}^{2+}$ absorption in Caco-2 cells is mediated by $\mathrm{Ca}_{\mathrm{v}} 1.3$ independently of both TRPV6 and calbindin- $\mathrm{D}_{9 \mathrm{~K}}[7]$.

\section{The role of apical membrane potential}

Review diagrams of intestinal $\mathrm{Ca}^{2+}$ absorption routinely present $\mathrm{V}_{\mathrm{m}}$ as about $-47 \mathrm{mV}$, the resting potential in the absence of nutrient. However, the fact that $\mathrm{V}_{\mathrm{m}}$ changes in response to luminal conditions, especially the presence or absence of nutrient, is rarely, if ever, mentioned. Our work suggests work suggests that changes in $\mathrm{V}_{\mathrm{m}}$ represent a very important variable.

The reason $\mathrm{Ca}_{\mathrm{v}} 1.3$ can operate effectively in small intestine is that its activation threshold is far more negative than that of $\mathrm{Ca}_{\mathrm{v}} 1.2$. In fact, the voltage-activation curve for $\mathrm{Ca}_{\mathrm{v}} 1.3$ overlaps with that of TRPV6 at a voltage very close to resting $\mathrm{V}_{\mathrm{m}}$ at $-47 \mathrm{mV}$. It therefore seems clear that TRPV6 and $\mathrm{Ca}_{\mathrm{v}} 1.3$ have complementary actions. TRPV6 acts between digestive periods, since it is activated by hyperpolarization and upregulated by low $\mathrm{Ca}^{2+}$ through the action of vitamin $\mathrm{D}$. $\mathrm{Ca}_{\mathrm{v}} 1.3$ operates during digestion, since it is activated by depolarization and can operate at high $\mathrm{Ca}^{2+}$ concentrations, being independent of calbindin- $\mathrm{D}_{9 \mathrm{~K}}$ and vitamin $\mathrm{D}$. Glucose-stimulated $\mathrm{Ca}^{2+}$ absorption, for example, occurs in diabetic rats, which are vitamin D-deficient.

A simple example how changes in $\mathrm{Ca}^{2+}$ absorption correlate with changes in $\mathrm{V}_{\mathrm{m}}$ was seen when perfusate of rat jejunum from a fed animal in vivo was switched from $20 \mathrm{mM}$ mannitol $(-2.9 \mathrm{mM}$ compared with resting $\left.\mathrm{V}_{\mathrm{m}}\right)$ to $20 \mathrm{mM}$ glucose $\left(+6.0 \mathrm{mV}\right.$ compared with resting $\left.\mathrm{V}_{\mathrm{m}}\right)$ and then to 20 $\mathrm{mM}$ glucose $+0.4 \mathrm{mM}$ phloridzin $\left(-1.9 \mathrm{mV}\right.$ compared with resting $\left.\mathrm{V}_{\mathrm{m}}\right)$. With mannitol, both channels, TRPV6 and $\mathrm{Ca}_{\mathrm{v}} 1.3$ each contributed $\sim 50 \%$ to total absorption. Switching from mannitol to glucose increased $\mathrm{Ca}^{2+}$ absorption almost 3-fold as a result of an increase in the nifedipine-sensitive component of almost 4-fold, so that $\mathrm{Ca}_{\mathrm{v}} 1.3$ was dominant. Repolarization of the membrane with phloridzin returned absorption to the same level as for mannitol. The changes are completely reversible and occur 
within minutes. It is vital to realize that different conditions or treatment of animals for absorption experiments can result in very different $\mathrm{V}_{\mathrm{m}}$ values. For example, some workers starve animals overnight to clear food from the gut. However, even such a short period changes resting $V_{m}$ from -47 $\mathrm{mV}$ for intestine from a fed rat to $-55 \mathrm{mV}$ for a starved rat. Intestine from a fed rat in the presence of glucose has a $V_{m}$ of $\sim-41 \mathrm{mV}$. This range of $14 \mathrm{mV}$ is similar to the difference in activation threshold, which allows $\mathrm{Ca}_{\mathrm{v}} 1.3$ to operate in intestine but not $\mathrm{Ca}_{\mathrm{v}} 1.2$. Unfortunately, there are remarkably few data on $\mathrm{V}_{\mathrm{m}}$ in the literature. Moreover, such essential data are not known for new conditions. What, for example, is the effect of a gene knockout on $\mathrm{V}_{\mathrm{m}}$ ?

\section{Conclusion:}

$\mathrm{Ca}_{\mathrm{v}} 1.3$ and TRPV6 have complementary properties. TRPV6 is activated by hyperpolarization, vitamin $\mathrm{D}$ and low $\mathrm{Ca}^{2+}$. TRPV6 therefore acts as a powerful scavenger between digestive periods. Such a role is vital, because plasma $\mathrm{Ca}^{2+}$ concentrations are greater than luminal between digestive periods. But for TRPV6, there would be massive loss of $\mathrm{Ca}^{2+}$ from the body by secretion. In contrast, $\mathrm{Ca}_{\mathrm{v}} 1.3$ is activated by depolarization and, on a short time scale, is independent of vitamin $\mathrm{D}$ and calbindin- $\mathrm{D}_{9 \mathrm{~K}}$. $\mathrm{Ca}_{\mathrm{v}} 1.3$ can act during digestion, when $\mathrm{Ca}^{2+}$ is plentiful and when TRPV6 is downregulated by both high $\mathrm{Ca}^{2+}$ and a more positive $\mathrm{V}_{\mathrm{m}}$.

Acknowledgments: This work was supported by The Wellcome Trust and the BBSRC

\section{References}

1. Kellett, G.L., Alternative perspective on intestinal calcium absorption: proposed complementary actions of Ca(v) 1.3 and TRPV6. Nutr Rev, 2011. 69(7): p. 347-70.

2. Bronner, F., Mechanisms of intestinal calcium absorption. J Cell Biochem, 2003. 88(2): p. 387-93.

3. Benn, B.S., et al., Active intestinal calcium transport in the absence of transient receptor potential vanilloid type 6 and calbindin-D9k. Endocrinology, 2008. 149(6): p. 3196-205.

4. Kellett, G.L., et al., Sugar absorption in the intestine: the role of GLUT2. Annu Rev Nutr, 2008. 28: p. 35-54.

5. Morgan, E.L., et al., A role for $\mathrm{Ca}(\mathrm{v}) 1.3$ in rat intestinal calcium absorption. Biochem Biophys Res Commun, 2003. 312(2): p. 487-93.

6. Mace, O.J., et al., Calcium absorption by Cav1.3 induces terminal web myosin II phosphorylation and apical GLUT2 insertion in rat intestine. J Physiol, 2007. 580(Pt. 2): p. 605-16.

7. Thongon, N., et al., Enhancement of calcium transport in Caco-2 monolayer through PKC $\{$ zeta $\}$-dependent Cav1.3-mediated transcellular and rectifying paracellular pathways by prolactin. Am J Physiol Cell Physiol, 2009. 


\title{
Endiandrin A, a phytoglucocorticoid that enhances colonic epithelial sodium channel (ENaC) function
}

\author{
Dana Kuntzsch ${ }^{\mathrm{a}}$, Theresa Bergann ${ }^{\mathrm{a}}$, Rohan A. Davis ${ }^{\mathrm{b}}$, Matthias F. Melzig ${ }^{\mathrm{c}}$, \\ Michael Fromm ${ }^{\mathrm{d}}$ and Jörg-Dieter Schulzke ${ }^{\mathrm{a}}$ \\ ${ }^{a}$ Dept. Gastroenterology Div. Nutritional Medicine, Campus Benjamin Franklin, Charité Berlin, Germany \\ ${ }^{b}$ Eskitis Institute, Griffith University, Brisbane, Australia \\ ${ }^{\mathrm{c}}$ Institute of Pharmaceutical Biology, Freie Universität Berlin, Germany \\ ${ }^{d}$ Institute of Clinical Physiology, Campus Benjamin Franklin, Charité Berlin, Germany
}

Introduction: The amiloride-sensitive epithelial sodium channel $(\mathrm{ENaC})$ plays a key role in electrogenic $\mathrm{Na}^{+}$absorption in the colon. Impaired $\mathrm{ENaC}$ function, a major factor in the pathogenesis of diarrhea in patients with inflammatory bowel disease (IBD), is improved by glucocorticoids (GCs) via glucocorticoidreceptor (GR)-dependent induction.

Aim: The aim was to characterize novel secondary plant compounds which either show selective GR binding and activation or synergistic effects in combination with the synthetic GC dexamethasone under inflammatory conditions. For endiandrin A, a cyclobutane lignan, isolated from the rainforest tree Endiandra anthropophagorum, GR binding activity was observed. Here, we analyzed the effect of endiandrin A on ENaC function in GR-expressing colonic HT-29/B6 (HT-29/B6-GR) cells.

Methods: ENaC-mediated $\mathrm{Na}^{+}$transport was characterized under the influence of dexamethasone, TNF- $\alpha$ and endiandrin A by electrophysiological measurements in the Ussing chamber. Moreover, GR transactivation was analyzed by gene reporter assay and ENaC mRNA levels were quantified by realtime polymerase chain reaction (PCR). Specific inhibitors for mitogen-activated protein kinases (MAPK) were used to clarify the signaling pathways.

Results: Endiandrin A alone showed only weak GR activity. However, when co-incubated with dexamethasone, endiandrin A significantly increased dexamethasone-induced GR transactivation in HT-29/B6-GR cells under inflammatory conditions. Analyses of $\mathrm{ENaC}$ function revealed that endiandrin A up-regulated $\beta$ - and $\gamma$-ENaC mRNA expression and amplified $\mathrm{ENaC}$-mediated sodium absorption when co-incubated with dexamethasone under inflammatory conditions. This effect was blocked by MAPK p38 inhibition indicating an involvement of p38.

Conclusion: Endiandrin A acts as a mild phytoglucocorticoid by enhancing glucocorticoid-stimulated $\mathrm{ENaC}$ activity via MAPK p38 pathway. This concept suggests a new approach for the development of multimodal drug therapies in inflammatory bowel disease. 


\title{
The role of STIM1 as intracellular $\mathrm{Ca}^{2+}$-sensing protein in the rat colonic epithelium
}

\author{
Kaoru Onodera, Martin Diener \\ Institute for Veterinary Physiology, Justus-Liebig-University Giessen, Germany
}

Introduction: In non-excitable cells, store-operated $\mathrm{Ca}^{2+}$ entry is the most important pathway to replenish intracellular $\mathrm{Ca}^{2+}$ stores. In many cells, the two proteins STIM (stromal interacting molecule) and Orai are assumed to be involved in the mediation of store-operated $\mathrm{Ca}^{2+}$ entry. STIM is located in the membrane of the endoplasmic reticulum, where it seems to act as an intracellular $\mathrm{Ca}^{2+}$ sensor. Orai, which localises in the plasma membrane, is probably a part of the $\mathrm{Ca}^{2+}$-release-activated $\mathrm{Ca}^{2+}$ channel (CRAC) or the arachidonate-regulated $\mathrm{Ca}^{2+}$ channel (ARC), and probably represents the (or part of the) pore-forming channel subunit. $\mathrm{Ca}^{2+}$ depletion within the endoplasmic reticulum leads to an oligomerization of STIM. STIM clusters and interacts with Orai to trigger store-operated $\mathrm{Ca}^{2+}$ channels into the open state. From both proteins, different subtypes, i.e. STIM1 - 2 and Orai1 - 3, respectively, are known. The existence of the two proteins in intestinal epithelial cells is unknown.

Aim: To investigated whether STIM1 or Orail exist in colonic epithelial cells and whether they exert a functional role.

Methods: For the experiments we used immunohistochemical techniques, Ussing chamber experiments, and imaging technology with fura-2.

Results: Immunohistochemical investigations revealed the expression of all subtypes of STIM and Orai in the rat colonic epithelium. Store depetion by incubation in $\mathrm{Ca}^{2+}$-free buffer combined with cyclopiazonic acid, led to a translocation of STIM1 not only to the basolateral, but also to the apical membrane of the enterocytes as observed with a confocal microscope. Ussing chamber experiments revealed a functional significance for $\mathrm{Ca}^{2+}$ influx across both membranes. After store-depletion, repletion of either apical or basolateral $\mathrm{Ca}^{2+}$ induced a chloride secretion measured as increase in short-circuit current. If basolateral $\mathrm{Ca}^{2+}$ channels were blocked with lanthanum, this increase in shortcircuit current was completely suppressed. A similar, albeit less pronounced, stimulation of $\mathrm{La}^{3+}-$ sensitive short-circuit current was observed, when $\mathrm{Ca}^{2+}$ was restored in the apical medium.

Conclusion: These data indicate that STIM1 and Orail exist in intestinal epithelial cells; they may function as $\mathrm{Ca}^{2+}$ channel after store-depletion. 